\title{
A Noninjection Reaction Route to CuInSe 2 Nanocrystals with Triethanolamine as the Complexing Agent
}

\author{
Wen-Long Liu, Meng-Qiang Wu, ${ }^{\dagger}$ Ru-Chao Zhou, Li-Dan Yan, Shu-Ren Zhang, ${ }^{\dagger}$ and Qi-Yi Zhang ${ }^{*}$ \\ School of Chemical Engineering, Sichuan University, Chengdu 610065, PR China. *E-mail: qyzhang-scu@163.com \\ ${ }^{\dagger}$ State Key Laboratory of Electronic Thin Films and Integrated Devices, University of Electronic Science and Technology \\ of China, Chengdu 610054, PR China \\ Received April 14, 2011, Accepted October 15, 2011
}

\begin{abstract}
The chalcopyrite-type CuInSe 2 is a remarkable material for thin film solar cells owing to its electronic structure and optical response. Single-phase sphere-like $\mathrm{CuInSe}_{2}$ nanocrystallite particles were prepared by a facile noninjection method with triethanolamine as the complexing agent and the solvent simultaneously. The period of the reaction was the key to form single-phase CuInSe $\mathrm{C}_{2}$ nanocrystals at $240{ }^{\circ} \mathrm{C}$. TEM, XRD, XPS, EDX investigations were performed to characterize the morphology and the detailed structure of as-synthesized $\mathrm{CuInSe} \mathrm{I}_{2}$ nanocrystals. All of the analysis results proved that the synthesized nanocrystals were pure phase and close to the stoichiometric ratio rather than a simple mixture. The band gap of the obtained $\mathrm{CuInSe}_{2}$ nanocrystals was $1.03 \pm 0.03 \mathrm{eV}$.
\end{abstract}

Key Words: CuInSe 2 , Nanocrystals, CIGS solar cells, Triethanolamine

\section{Introduction}

Copper indium diselenide $\left(\mathrm{CuInSe}_{2}\right)$-based solar cells have often been considered as one of the most promising ones for cost-effective power generation due to the highefficiency. In fact, devices based on this optical material and produced by three-stage co-evaporation with a modied surface termination under high vacuum have achieved a conversion efficiency up to around $20 \%{ }^{1}$ However, the high costs of widespread utilization of $\mathrm{CuInSe}_{2}$-based solar cells, using high-vacuum deposition techniques, have become a substantial hurdle to the thin Im PV market. Meanwhile, non-vacuum methods for formation of $\mathrm{CuIn}_{\mathrm{x}} \mathrm{Ga}_{1-\mathrm{x}} \mathrm{Se}_{2}(0 \leq \mathrm{x}$ $\leq 1)(\mathrm{CIGS})$ thin film photovoltaic absorbers can obviously reduce the cost of the fabrication and installation, which is necessary to compete with the traditionally generated power. What's more, the quality of CIGS layers obtained under nonvacuum are close to those made by vacuum methods, and some non-vacuum methods have been widely adopted. ${ }^{2}$ There are currently several interesting ways to form highquality CIGS films under non-vacuum condition. ${ }^{2}$ Particuarly, one approach is to chemically synthesize corresponding nanocrystals with tunable size and crystal phase, and then mixing these nanocrystals with suitable organic solvents so as to create a good dispersive and air-stable paint or ink. ${ }^{3}$ the particulate paint or ink can be assembled on both rigid and exible substrates using roll-to-roll process, which have the potential to make them cheap enough to large-scale manufacture. To obtain high-quality CIGS films, a key challenge is the synthetize of single-phase and nearly monodisperse semiconductor compounds nanocrystals. ${ }^{4}$ Therefore, developing facile routes that enable low-cost fabrication of inorganic colloidal nanocrystals ink to be used in a scalable coating process has attracted a great deal of attention.
To date, CuInSe 2 and related nanocrystals, a class of optical materials suitable for high-efficiency solar cell fabrication, have been synthesized by solid-state reaction, ${ }^{5}$ solvothermal, ${ }^{6,7}$ and hot-injection techniques. ${ }^{8-12}$ In a common sense, however, the nanocrystals synthesized by solvothermal techniques, which are conducted under the high temperature and pressure, are highly polydispersed, and generally require above 15 hours or even a few days to perform. ${ }^{13}$ Meanwhile, the hot-injection methods need complex devices with protective atmosphere and a rapid injection of precursors into a hot organic reaction medium. ${ }^{14}$ Furthermore, expensive oleylamine is needed as solvent and complexing agent via hot-injection technique to synthesize such multiple chalcopyrite nanocrystals. It is rarely reported that $\mathrm{CuInSe}_{2}$ nanocrystals with a band gap greater than $1.03 \mathrm{eV}$ are synthesized by hot-injection solution method, due to the fact that high-temperature is beneficial to nanocrystals growing in hot-injection processes. ${ }^{15}$

Here, we report a facile noninjection route to prepare highquality chalcopyrite $\mathrm{CuInSe} \mathrm{S}_{2}$ nanocrystals. A similar noninjection thermal decomposition method has also been successfully used in the synthesis of monodisperse pyramidal $\mathrm{CuInS}_{2}$ nanocrystals. $^{16}$ however, some toxic chemical, such as $n$-dodecanethiol and 1-octadecene, were used during the reaction process. In this work, the synthesis was carried out in triethanolamine (tEA). tEA was considered as the reaction medium and the complexing agent. The mechanism showed that the period of the reaction was the key to form single-phase $\mathrm{CuInSe} \mathrm{In}_{2}$ nanocrystals at a fixed temperature. The structure, composition, morphology and absorption spectra of $\mathrm{CuInSe}_{2}$ nanocrystals were investigated. This approach will allow low-cost fabrication of solar cell devices through these methods such as drop casting, ${ }^{4}$ spin coating, ${ }^{17}$ and printing. ${ }^{18}$ 


\section{Experimental}

Chemicals. Copper (I) chloride $(\mathrm{CuCl}, 99.99 \%)$, indium (III) chloride ( $\mathrm{InCl}_{3} \cdot 4 \mathrm{H}_{2} \mathrm{O}, 99.999 \%$ ), selenium ( $\mathrm{Se}, 99.999 \%$ ), and triethanolamine (tEA, 99t\%) were purchased from Sigma Aldrich and used without further purification.

Characterization. Phase purity and crystal structure of the samples were analyzed by powder X-ray diffraction (XRD; Rigaku D/max-Ra) using $\mathrm{Cu} K \alpha$ radiation. The morphology and element composition were characterized by Scanning electron microscopy (SEM; FEI Inspect F) equipped with an energy dispersive X-ray spectrometer (EDS; Oxford INCA Penta FET $\times 3)$. The average size $(\mathrm{P}=95 \%)$ of the nanocrystals was measured by SigmaScan Pro 2.0 software based on 5 different SEM images with a magnification rate of 80000 . The microstructure and morphology were characterized by Transmission electron microscopy (TEM; Tecnai G2 F20 S-TWIN)) with an accelerating voltage of $200 \mathrm{kV}$. The X-ray photoelectron spectra (XPS) were collected on an XSAM 800 XPS, using non-monochromatized $\mathrm{Mg} \mathrm{K} \alpha$ X-ray as the excitation source. UV-vis-NIR absorption spectra were carried out to evaluate the optical properties of $\mathrm{CuInSe}_{2}$ nanocrystals by using a Perkin Elmer Lambda $750 \mathrm{UV}$-vis spectrometer.

Sample Preparation. In a typical synthesis, two precursor solutions were prepared. For the preparation of a $\mathrm{Cu}$-tEA and In-tEA precursor solution, stoichiometric amounts of copper (I) chloride, indium (III) chloride were combined in tEA under inert conditions and heated to $180^{\circ} \mathrm{C}$ under the protection of the nitrogen. Over the course of an hour, the solution, marked solution A, gradually changed from colorless, to blue, and to orange red because of the dissolution of $\mathrm{CuCl}$ and $\mathrm{InCl}_{3}$ in tEA. Subsequently, the reaction flask was cooled down to room temperature. In a separate vial, A SetEA solution was obtained when selenium powder was absolutely dissolved in tEA, supported by the change in solution color from transparent to red-brown, and also the fact that the selenium powder disappeared soon after it was added into tEA. The Se-tEA precursor solution, labeled solution B, was prepared and then cooled down to room temperature.

Solution B was mixed into the reaction flask containing of the solution $\mathrm{A}$ at room temperature. After that, the mixture was heated to $240{ }^{\circ} \mathrm{C}$ to allow the nanocrystals to grow. All the experiments were done under the protection of the argon to ensure an inert atmosphere. After a xed time, such as $1 \mathrm{~h}$, $6 \mathrm{~h}$ and $10 \mathrm{~h}$, the products were carefully taken out, centrifuged, washed 3-5 times with methanol to remove any free $\mathrm{tEA}$, and dried under vacuum at the room temperature.

\section{Results and Discussion}

The main purpose of this work is to prepare single-phase $\mathrm{CuInSe}_{2}$ nanocrystals, so serial experiments were carried out on the basis of variety of time, and the products, obtained at different stages, were investigated using the XRD, as shown in Figure 1. From the XRD patterns, it can be found that the

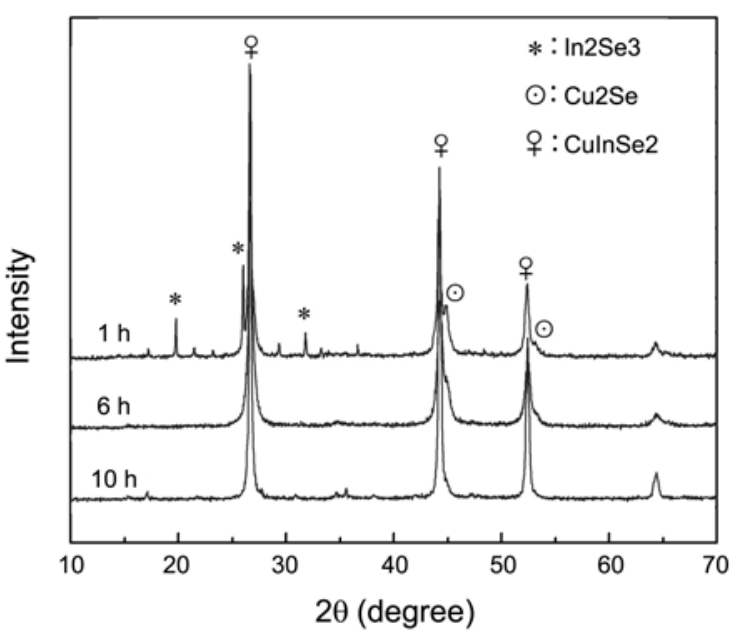

Figure 1. XRD patterns of as-synthesized nanocrystals from the $\mathrm{Cu}$-In-Se precursor with respect to the different reaction time, (a) 1 h, (b) $6 \mathrm{~h}$, and (c) $10 \mathrm{~h}$.

secondary phase of indium selenide and copper (I) selenide binary compound exist when the reaction time is less than 10 $\mathrm{h}$ when the temperature is xed at $240{ }^{\circ} \mathrm{C}$. All diffraction peaks of the as-synthesized nanocrystals, which react for 10 $\mathrm{h}$, match their standard crystal structure patterns for $\mathrm{CuInSe} \mathrm{I}_{2}$ (JCPDS 40-1487), and no other crystal phases are observed in the XRD patterns of the product.

According to X-ray diffraction scans of the product, the reaction process would be illustrated as follows: tEA is a weak base and its chemical formula is $\mathrm{N}\left(\mathrm{CH}_{2} \mathrm{CH}_{2} \mathrm{OH}\right)_{3}$. During the reaction, tEA served as both the reducing agent and the complexing agent. On the one hand, the selenium powder could be reduced to $\mathrm{Se}^{2-}$ ion by the reducing agent tEA at a high temperature. When the two precursor solutions were mixed, dissociative $\mathrm{Se}^{2-}$ might combine with $\mathrm{Cu}$ or In ions to form $\mathrm{Cu}_{2} \mathrm{Se}$ or $\mathrm{In}_{2} \mathrm{Se}_{3}$ in the tEA solution. $\mathrm{Cu}_{2} \mathrm{Se}$ and $\mathrm{In}_{2} \mathrm{Se}_{3}$ could react, and CuInSe $\mathrm{S}_{2}$ nanocrystals were produced. A similar phenomenon had also been reported, ${ }^{16,19}$ which was considered as a solid-liquid reaction mechanism. On the other hand, the chelating ability of tEA is attributed to the interaction of oxygen atoms on hydroxyl groups with metal ions. As the complexing constant of $\left(\mathrm{Cu}-\mathrm{tEA}_{2}\right)^{2+}$ is $1 \times 10^{6},{ }^{20}$ apparently, tEA is a good candidate for the chelating agent. As the metal ion-tEA is a chelate, a steady stream of metal ions was provided for the reaction process, and then $\mathrm{CuInSe}_{2}$ nanocrystals were consistently deposited.

The morphology of the obtained nanocrystals was investigated by TEM observation. Figure 2(a) shows the TEM image of the $\mathrm{CuInSe}_{2}$ synthesized at $240{ }^{\circ} \mathrm{C}$ for $10 \mathrm{~h}$, indicating that the outward appearance of the as-prepared $\mathrm{CuInSe}_{2}$ nanocrystals seems like spheroid. The size of the $\mathrm{CuInSe}_{2}$ nanocrystals ranges from $27.2 \mathrm{~nm}$ to $53.1 \mathrm{~nm}$, which can be attributed to the different growth time at a high temperature.

The high-resolution TEM (HRTEM) image (Figure 2(b)) of the as-synthesized nanocrystals shows that the lattice fringe gives an interplanar spacing of $0.33 \mathrm{~nm}$, which matches well with the distance of the (112) plane of the standard 

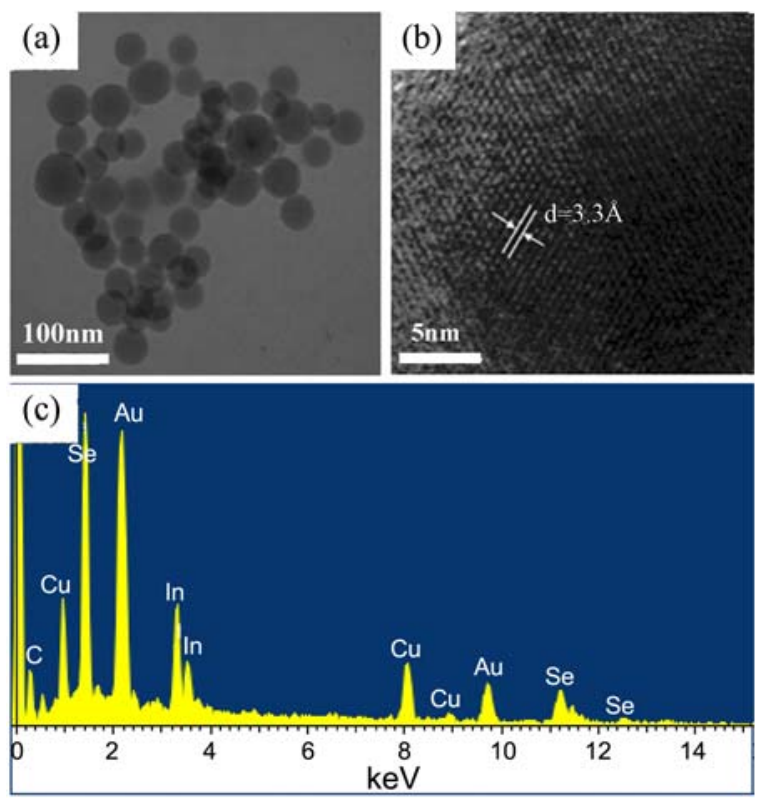

Figure 2. (a) TEM and (b) HR-TEM image of the CuInSe nanocrystals obtained at $240{ }^{\circ} \mathrm{C}$ for $10 \mathrm{~h}$, (c) EDS spectrum showing the composition of the nanocrystals.
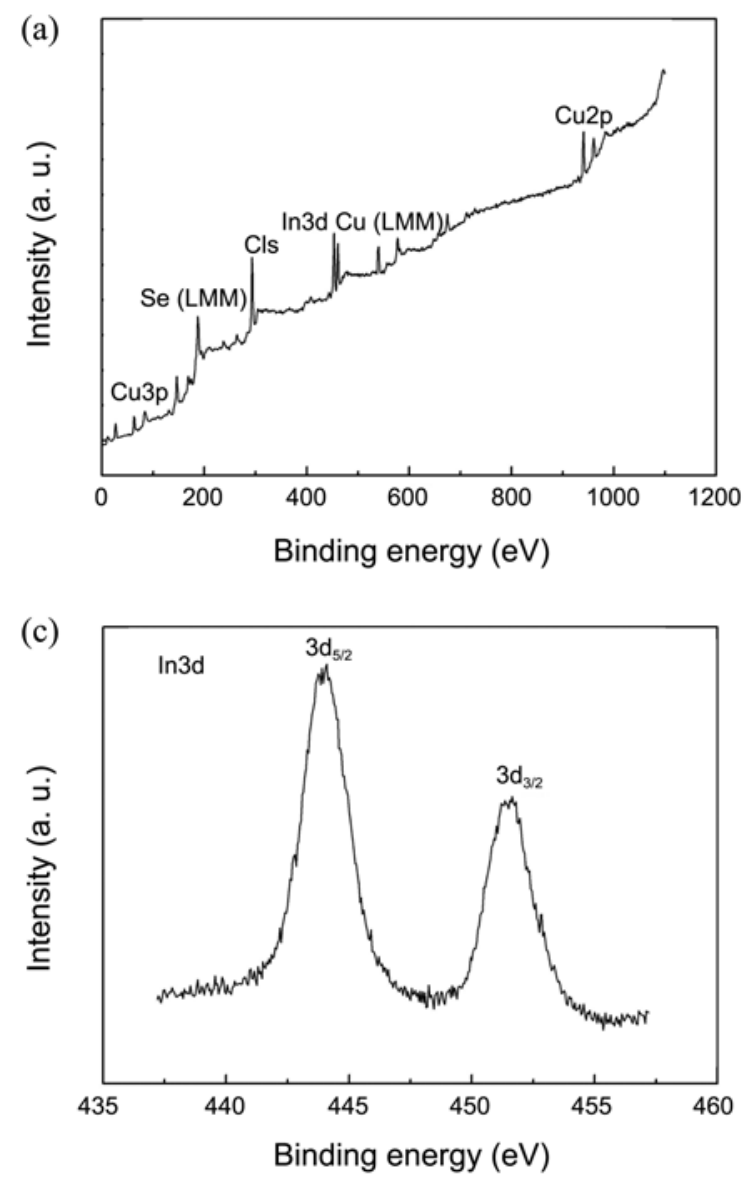

tetragonal CuInSe 2 . Both HRTEM and XRD conrmed that pure-phase $\mathrm{CuInSe} \mathrm{S}_{2}$ nanocrystals with a tetragonal chalcopyrite structure were obtained. The formation of such nanocrystals may involve the reactions of $\mathrm{Cu}_{2} \mathrm{Se}$ with $\mathrm{In}_{2} \mathrm{Se}_{3}$, decomposed from $\mathrm{CuCl}$ and $\mathrm{InCl}_{3}$ respectively, in the presence of tEA.

Additionally, the energy dispersive X-ray spectrum (EDS) of the nanocrystals (Figure 2(c)) microanalysis was performed by randomly selecting single particles in the TEM image. No appreciable impurity is observed in the spectra. A very small $\mathrm{C}$ peak and a significant $\mathrm{Au}$ peak, which come from the metallization process, were detected in the EDX spectrum. The results show that the atomic ratio of $\mathrm{Cu}: \mathrm{In}: \mathrm{Se}$ is 1.05:0.97:1.86, which further demonstrats that these nanocrystals are single phase and close to stoichiometric. The nanocrystals are slightly copper-rich and selenium-deficient. The lower Se content may be attributed to the oxidation of the samples during the analysis.

X-ray photoelectron spectroscopy (XPS) analysis was used to confirm the valence states of the CuInSe $\mathrm{C}_{2}$ nanocrystals as shown in Figure 3 . The $\mathrm{Cu} 2 \mathrm{p}$, In $3 d$, and Se $2 \mathrm{p}$ core levels were examined respectively. The binding energies obtained in the XPS analysis were corrected for
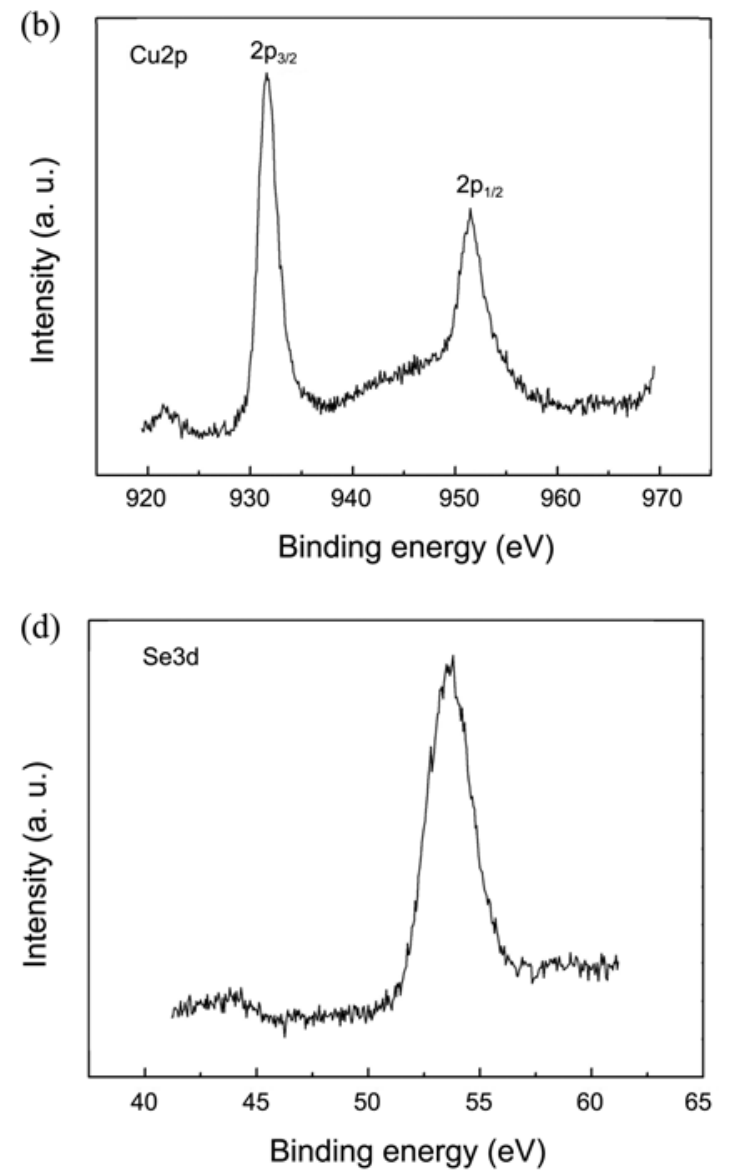

Figure 3. XPS of the CuInSe 2 nanocrystals synthetized for $10 \mathrm{~h}$ in tEA. (a) Survey spectrum. (b) The XPS spectrum of Cu $2 \mathrm{p}$. Two narrow peaks at 931.75 and $951.46 \mathrm{eV}$, matched well with the reported binding energy for $\mathrm{Cu}$ (I). (c) The XPS spectrum of In $3 \mathrm{~d}$. Two peaks located at 444.01 and $451.52 \mathrm{eV}$, indicate In (III). (d) The XPS spectrum of Se 3d. Peak located at $53.64 \mathrm{eV}$, consistent with Se in selenide phases. 


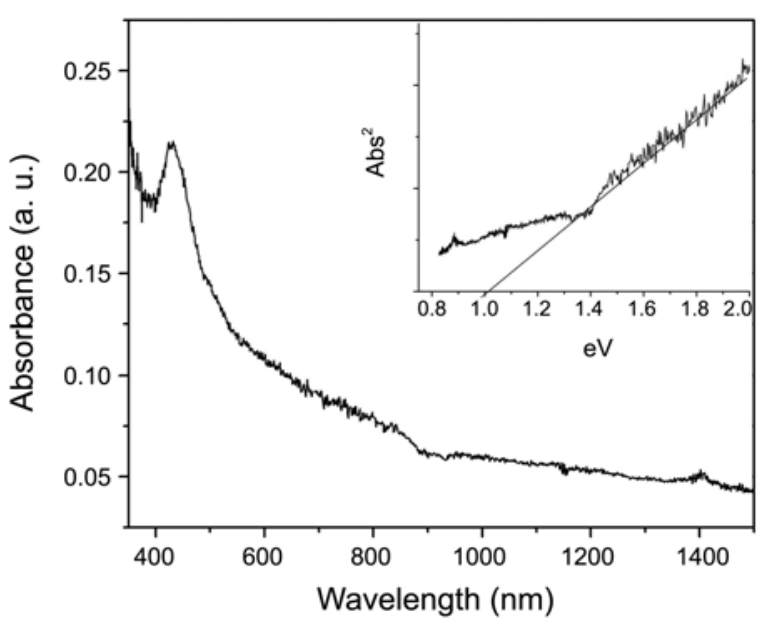

Figure 4. UV-vis-NIR absorption spectrum of the obtained $\mathrm{CuInSe}_{2}$ nanocrystals. The estimated band gap energy is $1.06 \pm$ $0.03 \mathrm{eV}$.

specimen charging by referencing the $\mathrm{C} 1 \mathrm{~s}$ to $284.60 \mathrm{eV}$. The occurrence of $\mathrm{O}$ is considered as a consequence of $\mathrm{O}_{2}$ adsorption in the air. The appearance of the characteristic $\mathrm{Cu}$ $2 \mathrm{p}_{3 / 2}$ peak at $931.7 \mathrm{eV}, \mathrm{Cu} 2 \mathrm{p}_{1 / 2}$ peak at $951.5 \mathrm{eV}$, which is showed in Figure 3(b), confirm that the existence of $\mathrm{Cu}^{+}$. In addition, there is no $\mathrm{Cu} 2 \mathrm{p}_{3 / 2}$ satellite peak at about $942 \mathrm{eV}$ that is attributed to $\mathrm{Cu}^{2+}$. Detailed scan for In $3 \mathrm{~d}$ (Figure 3(c)) shows two peaks locate at $444.01 \mathrm{eV}$ and $451.52 \mathrm{eV}$, match well with the reported binding energy for In(III). ${ }^{9}$ There is only one peak of Se 3d at binding energy $53.64 \mathrm{eV}$, which is consistent with Se in selenide phases. In conclusion, the XPS spectra of the three constituent elements indicate that $\mathrm{Cu}$ (I), In (III), Se (II) are consistent with those reported in literature for $\mathrm{CuInSe}_{2} ., 21$

In order to evaluate the application of this facile noninjection synthesis method to solar cells, the optical properties has been studied. Figure 4 shows the UV-vis-NIR absorption spectroscopy to evaluate the optical properties of the nanocrystals suspended homogenously in toluene solution. It shows the characteristic spectrum of $\mathrm{CuInSe}_{2}$ ranges from $350 \mathrm{~nm}$ to $1500 \mathrm{~nm}$. The variation of $(\alpha \mathrm{hv})^{2}$ as a function of the photon energy (hv) is also shown. An approximate linear relationship is obtained, and the Eg of the as-synthesized $\mathrm{CuInSe}_{2}$ nanocrystals is therefore estimated to be $1.06 \pm 0.03 \mathrm{eV}$ from the intercept of the linear portion of the curves with the photon energy axis. So the band gap energy is consistent with the reported value of $1.03 \mathrm{eV}$ for the $\mathrm{CuInSe}_{2}$ nanocrystals and is close to the bulk chalcopyrite $\mathrm{CuInSe}_{2}(1.10 \mathrm{eV}){ }^{22} \mathrm{Y}$. Wang and co-workers have reported that smaller nanocrystals are needed to observe significant quantum confinement effects when the particle size is comparable with the Bohr radius of excitons. ${ }^{23}$ The fact suggests that the quantum size effect is scarcely observed for $\mathrm{CuInSe}_{2}$ nanocrystals of sizes larger than $30 \mathrm{~nm}$. The $\mathrm{CuInSe}_{2}$ nanocrystals may strongly absorb throughout the entire visible region of the spectrum, resulting in a black color of the material.

\section{Conclusion}

A facile noninjection reaction route is developed for the synthesis of single-phase $\mathrm{CuInSe}_{2}$ nanocrystals, by using tEA as the complexing agent and the solvent. This route is low-cost and based on green chemistry with a large-scale capability. This noninjection synthesis foretells an easy handling with high reproducibility, low-cost but high-yield (about 85\%).

XRD, XPS, EDS, HR-TEM analyses conrm that the structure and composition of the nanocrystals, prepared by this method, correspond to those of pure phase CuInSe 2 .

The UV-vis-NIR data show that the band gap of the obtained CuInSe $\mathrm{S}_{2}$ nanocrystals are in the range of 1.03-1.09 $\mathrm{eV}$, which is of interest for its photovoltaic applications.

Acknowledgments. This work has been supported by Science and Technology Supporting Project of Sichuan Province (Contract No. 2009FZ20073). The authors thank Ming Liu (Analytical and Testing Center of Sichuan University, Chengdu, P.R. China) for the TEM images taking.

\section{References}

1. Repins, I.; Contreras, M. A.; Egaas, B.; DeHart, C.; Scharf, J.; Perkins, C. L.; To, B.; Noufi, R. Prog. Photovolt.: Res. Appl. 2008, 16, 235 .

2. Hibberd, C. J.; Chassaing, E.; Liu, W.; Mitzi, D. B.; Lincot, D.; Tiwari, A. N. Prog. Photovolt.: Res. Appl. 2010, 18, 434.

3. Habas, S. E.; Platt, H. A. S.; van Hest, M. F. A. M.; Ginley, D. S. Chem. Rev. 2010, 110, 6594.

4. Guo, Q.; Kim, S. J.; Kar, M.; Shafarman, W. N.; Birkmire, R. W.; Stach, E. A.; Agrawal, R.; Hillhouse, H. W. Nano Lett. 2008, 8, 2982.

5. Schoen, D. T.; Peng, H. L.; Cui, Y. J. Am. Chem. Soc. 2009, 131, 7973.

6. Chang, J.; Han, J. E.; Jung, D. Y. Bull. Korean Chem. Soc. 2011, 32,434 .

7. Olejnicek, J.; Kamler, C. A.; Mirasano, A.; Martinez-Skinner, A. L.; Ingersoll, M. A.; Exstrom, C. L.; Darveau, S. A.; HugueninLove, J. L.; Diaz, M.; Ianno, N. J.; Soukup, R. J. Sol. Energ. Mat. Sol. C 2010, 94, 8.

8. Tang, J.; Hinds, S.; Kelley, S. O.; Sargent, E. H. Chem. Mater. 2008, 20, 6906.

9. Norako, M. E.; Brutchey, R. L. Chem. Mater. 2010, 22, 1613.

10. Pan, D. C.; An, L. J.; Sun, Z. M.; Hou, W.; Yang, Y.; Yang, Z. Z.; Lu, Y. F. J. Am. Chem. Soc. 2008, 130, 5620.

11. Guo, Q.; Ford, G. M.; Hillhouse, H. W.; Agrawal, R. Nano Lett. 2009, 9, 3060.

12. Pan, D. C.; Wang, X. L.; Zhou, Z. H.; Chen, W.; Xu, C. L.; Lu, Y. F. Chem. Mater. 2009, 21, 2489.

13. Chen, H.; Yu, S. M.; Shin, D. W.; Yoo, J. B. Nanoscale. Res. Lett. 2010, 5, 217.

14. Zhang, D. Q.; Li, G. S.; Yu, J. C. Cryst. Growth. Des. 2009, 9, 2812.

15. Liu, T. Y.; Li, M. J.; Ouyang, J. Y.; Zaman, M. B.; Wang, R. B.; Wu, X. H.; Yeh, C. S.; Lin, Q.; Yang, B.; Yu, K. J. Phys. Chem. C 2009, 113, 2301.

16. Zhong, H. Z.; Lo, S. S.; Mirkovic, T.; Li, Y. C.; Ding, Y. Q.; Li, Y. F.; Scholes, G. D. ACS nano. 2010, 4, 5253.

17. Chung, J.; Kim, S. J. Bull. Korean Chem. Soc. 2010, 31, 2695.

18. Jeong, S.; Hu, L. B.; Lee, H. R.; Garnett, E.; Choi, J. W.; Cui, Y. 
Nano Lett. 2010, 10, 2989

19. Xu, J.; Lee, C. S.; Tang, Y. B.; Chen, X.; Chen, Z. H.; Zhang, W. J.; Lee, S. T.; Zhang, W. X.; Yang, Z. H. ACS nano. 2010, 4, 1854.

20. Whang, T. J.; Hsieh, M. T.; Kao, Y. C.; Lee, S. J. Appl. Surf. Sci. 2009, 255,4600 .

21. Kazmerski, L. L.; Jamjoum, O.; Ireland, P. J.; Deb, S. K.; Mickelsen,
R. A.; Chen, W. J. Vac. Sci. Technol. 1981, 19, 467.

22. Castro, S. L.; Bailey, S. G.; Raffaelle, R. P.; Banger, K. K.; Hepp, A. F. Chem. Mater. 2003, 15, 3142.

23. Wang, Y.; Suna, A.; Mahler, W.; Kasowski, R. J. Chem. Phys. $1987,87,7315$. 